Article

\title{
Ge-Sb-Te Chalcogenide Thin Films Deposited by Nanosecond, Picosecond, and Femtosecond Laser Ablation
}

\author{
Georgiana Bulai ${ }^{1}$, Oana Pompilian ${ }^{2,3}{ }^{\oplus}$, Silviu Gurlui ${ }^{4}$, Petr Nemec ${ }^{5}$, , Virginie Nazabal ${ }^{5,6}$, \\ Nicanor Cimpoesu ${ }^{7}$, Bertrand Chazallon ${ }^{2}$ and Cristian Focsa ${ }^{2, *}$ \\ 1 Integrated Centre for Environmental Science Studies in the North-East Development Region-CERNESIM, \\ “Al. I. Cuza" University of Iasi, 700506 Iasi, Romania; georgiana.bulai@uaic.ro \\ 2 Université de Lille, CNRS, UMR 8523-PhLAM-Physique des Lasers, Atomes et Molécules, CERLA-Centre \\ d'Etudes et de Recherches Lasers et Applications, Lille F-59000, France; oana.pompilian@inflpr.ro (O.P.); \\ bertrand.chazallon@univ-lille.fr (B.C.) \\ 3 National Institute for Lasers, Plasma and Radiation Physics, RO-077125 Magurele-Bucharest, Romania \\ 4 Faculty of Physics, “Al. I. Cuza” University of Iasi, 700506 Iasi, Romania; sgurlui@uaic.ro \\ 5 Faculty of Chemical Technology, University of Pardubice, 53210 Pardubice, Czech Republic; \\ Petr.Nemec@upce.cz (P.N.); virginie.nazabal@univ-rennes1.fr (V.N.) \\ 6 Université de Rennes 1, CNRS, ISCR (Institut des Sciences Chimiques de Rennes)-UMR 6226, \\ F-35000 Rennes, France \\ 7 Faculty of Materials Science and Engineering, “Gheorghe Asachi” Technical University of Iasi, 700050 Iasi, \\ Romania; nicanor.cimpoesu@tuiasi.ro \\ * Correspondence: cristian.focsa@univ-lille.fr; Tel.: +33-320-33-64-84
}

Received: 23 March 2019; Accepted: 23 April 2019; Published: 1 May 2019

\begin{abstract}
Ge-Sb-Te thin films were obtained by ns-, ps-, and fs-pulsed laser deposition (PLD) in various experimental conditions. The thickness of the samples was influenced by the Nd-YAG laser wavelength, fluence, target-to-substrate distance, and deposition time. The topography and chemical analysis results showed that the films deposited by ns-PLD revealed droplets on the surface together with a decreased Te concentration and Sb over-stoichiometry. Thin films with improved surface roughness and chemical compositions close to nominal values were deposited by ps- and fs-PLD. The X-ray diffraction and Raman spectroscopy results showed that the samples obtained with ns pulses were partially crystallized while the lower fluences used in ps- and fs-PLD led to amorphous depositions. The optical parameters of the ns-PLD samples were correlated to their structural properties.
\end{abstract}

Keywords: pulsed laser deposition; chalcogenide thin films; Raman spectroscopy; spectroscopic ellipsometry

\section{Introduction}

Important advances in nonvolatile solid state memory devices were driven by the discovery of Ge-Sb-Te (GST) alloys along the GeTe-Sb ${ }_{2} \mathrm{Te}_{3}$ tie-line in the mid-1980s [1]. Phase change (PC) memories are based on changes in optical properties and electrical conductivity of chalcogenide materials upon a rapid amorphous-to-crystalline phase transition and vice versa. These two states must present a high enough contrast in electrical resistivity or other (optical) parameters in order to be identified. The rapid changes from an amorphous (high electrical resistivity) to crystalline structure (low electrical resistivity) are induced by the Joule effect using an electric current pulse [2]. Depending on the intensity and duration of the pulses, the PC memory cells can be written or erased. The rapid laser-induced 
crystallization with large property changes represented the grounds for many research studies [3-9]. For applications in data storage devices, other properties such as a good thermal stability of the amorphous phase and the possibility of applying a large number of write-erase cycles need to be considered. The investigations of Yamada et al. [1] on 100-nm-thick GST films deposited by electron beam evaporation revealed that their crystallization temperatures were larger than room temperature but accessible for phase transitions by electric pulses. The laser-induced crystallization time of these samples was below $70 \mathrm{~ns}$, which ensured a rapid recording. The degree of the optical change $n, k$ (crystalline)-n,k (amorphous) on the GeTe-Sb $\mathrm{Te}_{3}$ pseudo-binary line increases with an increasing Ge content [10], but GST chalcogenides with higher Sb concentrations present faster phase changes. Thus, the study of Ge-Sb-Te-based compounds in various compositions is essential when developing phase change devices with remarkable characteristics [11].

Several methods for chalcogenide thin film deposition have been employed to date such as spin coating [12], magnetron sputtering [13,14], thermal evaporation [15], atomic layer deposition [16], and metal organic vapor phase epitaxy [17]. Among these, the Pulsed Laser Deposition (PLD) technique is suitable for the thin film growth of complex materials with a good adhesion to the substrate and a high homogeneity. Chalcogenide thin films with a low surface roughness were reported in Reference [14]. The films deposited by PLD presented lower bandgap values than the samples obtained by sputtering [14]. Musgraves et al. [15] compared the structural, optical, and electrical properties of Ge-Sb-S thin films deposited by two methods: thermal evaporation (TE) and laser ablation. The chemical composition analysis revealed a slight variation of the $\mathrm{Sb} / \mathrm{S}$ ratio from the stoichiometric value in the TE samples, while the PLD thin films replicated the atomic percentages of the main elements from the target. The refractive indices of the as-deposited (amorphous) PLD thin films presented higher values that the ones observed for the TE samples and even than the ones of the bulk material. PLD epitaxial $\mathrm{Ge}_{2} \mathrm{Sb}_{2} \mathrm{Te}_{5}$ thin films were obtained by Hilmi et al. [18]. However, their results also showed a decreased deposition rate as the substrate temperature was augmented, indicating a strong desorption during the deposition process. Similar observations were reported in Reference [19]. The studies done by Song et al. [20] and Boschker et al. [21] showed that the high adatom energy (proportional to the kinetic energy of the ejected particles that arrived at the substrate surface) during the pulsed laser deposition process influenced the stoichiometry and roughness of the film through preferential resputtering. However, photoexcited desorption [22] and in situ plasma plume diagnostics can offer information on the velocity of the ejected species [23-26].

This paper presents the main experimental results of an extensive systematic study on thin films of chalcogenide materials based on the ternary Ge-Sb-Te diagram. The films were deposited by laser ablation in various experimental conditions, varying laser parameters (pulse duration, repetition rate, wavelength, and fluence), target-to-substrate distance, and deposition time. The investigated materials were the endpoints of the $\mathrm{GeTe}-\mathrm{Sb}_{2} \mathrm{Te}_{3}$ pseudo-binary line and the intermediate stable phases containing different proportions of these two structures: $\mathrm{GeSb}_{2} \mathrm{Te}_{4}$ (GST 124), $\mathrm{GeSb}_{4} \mathrm{Te}_{7}$ (GST 147), and $\mathrm{Ge}_{2} \mathrm{Sb}_{2} \mathrm{Te}_{5}$ (GST 225).

\section{Materials and Methods}

The Ge-Sb-Te thin films were synthesized by Pulsed Laser Deposition using an experimental setup described in detail in previous papers [24,27-29]. Two types of lasers were used for target ablation: a Nd-YAG laser (Continuum Surelite III-10) with a 10-ns pulse width and a 10-Hz repetition rate for which we used all four harmonics $(266,355,532$, and $1064 \mathrm{~nm}$ ) and a Ti-Sa laser (Spectra Physics) with pulse durations of $2 \mathrm{ps}$ and $120 \mathrm{fs}$ and with a repetition rate of up to $1 \mathrm{kHz}$. The bulk materials $(\mathrm{GeTe}$, $\mathrm{GeSb}_{2} \mathrm{Te}_{4}, \mathrm{Ge}_{2} \mathrm{Sb}_{2} \mathrm{Te}_{5}, \mathrm{GeSb}_{4} \mathrm{Te}_{7}$, and $\mathrm{Sb}_{2} \mathrm{Te}_{3}$ ) were prepared by the melt quenching method using high-purity elements ( $5 \mathrm{~N}$ purity) and a melting temperature of $960{ }^{\circ} \mathrm{C}$. The obtained polycrystalline targets were placed inside the stainless-steel vacuum chamber on a micrometric precision 3D-axis manipulator, while the substrate (single crystalline (100) Silicon and glass) was positioned at different distances in front of the target. The pressure during the depositions was kept in approximately 
the $10^{-5}$ Torr range using a turbomolecular pump. The other varied experimental parameters were the target-to-substrate distance $(15-60 \mathrm{~mm})$, fluence $\left(0.1-10 \mathrm{~J} / \mathrm{cm}^{2}\right)$, and deposition time (5-60 $\left.\mathrm{min}\right)$. Considering the numerous deposited samples, details on the growth conditions of each film are given as the paper proceeds.

The morphological, compositional, structural, and optical properties of the synthesized films were studied using various techniques. The sample thickness was estimated using stylus profilometry (Dektak 6M). Images of the surface topography were obtained by optical microscopy (Olympus BXFM free-space confocal microscope, Olympus Europa, Hamburg, Germany) and scanning electron microscopy (Tescan Vega II LMH, Tescan, Brno, Czech Republic), using different magnifications. The chemical composition of the samples was studied by Energy-dispersive X-ray spectroscopy (EDS, Tescan Vega II LMH, Tescan, Brno, Czech Republic). Time of Flight-Secondary Ion Mass Spectroscopy (ToF-SIMS, ION-TOF 5, IONTOF, Münster, Germany) was used to analyze the distribution of the main elements on a $500 \times 500 \mu \mathrm{m}$ area on the sample surface in negative and positive polarity. In-depth profiles were obtained by sputtering $300 \times 300 \mu \mathrm{m}$ section with $\mathrm{O}_{2}$ (for positive polarity) or Cs (for negative polarity) ion beams and analyzing a $100 \times 100 \mu \mathrm{m}$ inner (centered) surface with $\mathrm{Bi}_{3}^{+}$ion beam ( $25 \mathrm{kV}, 1 \mathrm{pA})$. Raman spectroscopy measurements were performed using an InVia Reflex spectrometer (Renishaw, $250 \mathrm{~mm}$ focal length, Renishaw SA, Champs-sur-Marne, France) equipped with an Ar laser source (514.5 nm wavelength, $36 \mathrm{~mW}$ laser power). Room temperature X-ray diffraction (Bruker AXS- $\mathrm{Cu} \mathrm{K} \alpha$ radiation) patterns were required in the $5-65^{\circ} 2 \theta$ range with $0.02^{\circ}$ step and 5-s step times. The optical properties were investigated by variable angle spectroscopic ellipsometry (VASE, J.A. Woollam Co., Inc., Lincoln, NE, USA) in the 0.54-4.13 eV (2300-300 nm) spectral region.

\section{Results and Discussion}

\subsection{Topography, Chemical Composition, and Structural Properties}

\subsubsection{Nanosecond Laser Ablation}

The optical microscopy images and thickness profiles revealed that the surface of the sample deposited by nanosecond laser ablation was affected by the presence of droplets, their density being dependent on the fluence. These microscopic particles deposited on the substrate/film surface can have several origins: dislodging of existing or laser-produced protruding target surface features, subsurface superheating, splashing of the molten surface layer, or condensation from vapor species due to supersaturation [30]. In femtosecond laser ablation, there are mainly nonthermal processes involved which end with the Coulomb explosion as the main ejection mechanism, while in nanosecond laser ablation, the longer pulse width leads to strong thermal effects. In this temporal range, the thermal mechanisms are predominant and determine the thermal damage of the lattice (homogeneous melting).

Another important parameter that can have great influence on the microstructure of the deposited samples is the laser wavelength which, depending on the thermal properties of the material, can determine the ejection of different sized particles. Near-UV wavelengths offer higher photon energies and shorter penetration depths which can reduce the thermal effects when nanosecond pulse lasers are used. Thus, the deposition with the 266-nm laser radiation presents an advantage, especially when lower fluences are used. Large area depositions of GeTe were accomplished using the 266-nm radiation of the Nd-YAG laser and a lower fluence $\left(1.2 \mathrm{~J} / \mathrm{cm}^{2}\right)$ compared to the other GeTe samples. The glass substrate was placed at a distance of $6 \mathrm{~cm}$ from the target, and the deposition time was $30 \mathrm{~min}$. With these deposition conditions, improved results related to surface microstructure were obtained. The lower fluence used for ablation determined the deposition not only of a few droplets but also of a thinner thin film. However, one should consider that the thickness value of $120 \mathrm{~nm}$ was obtained when analyzing the ends of the deposited area but that the thin film can present a greater thickness in the center region due to the strong directionality of the ablation plume on the normal to the target surface. Although a larger target-to-substrate distance, a shorter deposition time, and a lower fluence 
were used to deposit the film on glass substrate, the thickness was still reasonable $(120 \mathrm{~nm})$ while the uniformity was improved.

For a comparative study, Ge-Sb-Te thin films were deposited using the 266-nm laser wavelength in the same other conditions: laser fluence $3.81 \mathrm{~J} / \mathrm{cm}^{2}$, deposition time $60 \mathrm{~min}$, and target-substrate distance of $3 \mathrm{~cm}$. Table 1 summarizes the stylus profilometer thin films thickness measurements and their elemental composition, as measured by EDS. The latter reveals a Ge over-stoichiometry in the GeTe samples and an increased $\mathrm{Sb}$ content in the $\mathrm{Sb}_{2} \mathrm{Te}_{3}$ and $\mathrm{Ge}-\mathrm{Sb}$-Te-based thin films. The concentration errors were approximately $1-2$ at $\%$. These main trends in composition variation were also observed when different conditions were used for thin film deposition. However, smaller deviations from the nominal values were found for the $\mathrm{GeTe}$ and $\mathrm{Sb}_{2} \mathrm{Te}_{3}$ samples deposited at higher target-to-substrate distances. For the intermediate compositions $\left(\mathrm{GeSb}_{2} \mathrm{Te}_{4}, \mathrm{GeSb}_{4} \mathrm{Te}_{7}\right.$, and $\left.\mathrm{Ge}_{2} \mathrm{Sb}_{2} \mathrm{Te}_{5}\right)$, this content evolution with a target-to-substrate distance was not observed.

Table 1. The thickness (stylus profilometry) and elemental composition (EDS) of the thin films deposited using the $266-\mathrm{nm}$ radiation with a $3.81 \mathrm{~J} / \mathrm{cm}^{2}$ fluence, a $60-\mathrm{min}$ deposition time, and a 3-cm target-substrate distance.

\begin{tabular}{|c|c|c|c|c|}
\hline \multirow{2}{*}{$\begin{array}{l}\text { Target Nominal at } \% \\
\text { Composition }\end{array}$} & \multirow{2}{*}{$\begin{array}{l}\text { Thickness } \\
\text { (nm) }\end{array}$} & \multicolumn{3}{|c|}{ EDS Measured Thin Film Composition (at \%) } \\
\hline & & $\mathrm{Ge}$ & $\mathrm{Sb}$ & $\mathrm{Te}$ \\
\hline $\begin{array}{l}\mathrm{GeTeGe} \\
{ }_{50} \mathrm{Te}_{50}\end{array}$ & 600 & 62.68 & - & 37.32 \\
\hline $\begin{array}{c}\mathrm{Sb}_{2} \mathrm{Te}_{3} \\
\mathrm{Sb}_{40} \mathrm{Te}_{60}\end{array}$ & 620 & - & 48.78 & 51.22 \\
\hline $\begin{array}{c}\mathrm{GeSb}_{2} \mathrm{Te}_{4} \\
\mathrm{Ge}_{14.28} \mathrm{Sb}_{28.57} \mathrm{Te}_{57.14}\end{array}$ & 600 & 13.14 & 35.78 & 51.08 \\
\hline $\begin{array}{c}\mathrm{GeSb}_{4} \mathrm{Te}_{7} \\
\mathrm{Ge}_{8.33} \mathrm{Sb}_{33.33} \mathrm{Te}_{58.33}\end{array}$ & 600 & 9.57 & 39.8 & 50.63 \\
\hline $\begin{array}{c}\mathrm{Ge}_{2} \mathrm{Sb}_{2} \mathrm{Te}_{5} \\
\mathrm{Ge}_{22.22} \mathrm{Sb}_{22.22} \mathrm{Te}_{55.55}\end{array}$ & 690 & 12.75 & 31.81 & 55.45 \\
\hline
\end{tabular}

A higher Ge concentration was also reported in References [6,31,32] for Ge-Sb-Te thin films deposited by PLD using a KrF excimer laser $(248 \mathrm{~nm}, 30 \mathrm{~ns}, 20 \mathrm{~Hz})$ at a fluence of $2.6 \mathrm{~J} / \mathrm{cm}^{2}$. However, the recorded deviations were lower than the ones reported in this paper. The large deviations from the nominal composition in this study can be explained by the higher fluence used for target ablation. The high temperature induced at laser-target interaction could induce a more rapid evaporation of Te with respect to Ge, depending on the chemical properties of each species. The tellurium deficiency can be caused by its higher volatility compared to $\mathrm{Ge}$ or $\mathrm{Sb}$ [24].

The distribution of $\mathrm{Ge}, \mathrm{Sb}$, and Te in the thin film volume was analyzed by ToF-SIMS depth profiling. Figure 1 presents the obtained profiles for the $\mathrm{Ge}_{1} \mathrm{Sb}_{4} \mathrm{Te}_{7}$ thin film.

A uniform depth profile distribution was observed for $\mathrm{Ge}_{1} \mathrm{Sb}_{4} \mathrm{Te}_{7}$ thin films where three samples with different thicknesses were analyzed. However, an elevated Te content was observed at the region close to the thin film surface. This can come also from matrix effect due to oxidation at interface. As Te has a more pronounced metallic character, it can be more affected by this. The same behavior was observed in the GST 225 thin films deposited by Krusin-Elbaum et al. [33] by magnetron sputtering on Si substrate. Their work revealed that the deposited samples present a Te segregation on grain boundaries and surfaces. The composition of the main elements on the thin film surface was determined in Reference [32] by proton-induced X-ray emission (PIXE) and Rutherford back-scattering (RBS). 




Figure 1. The ToF-SIMS depth profiles obtained in a positive polarity of the $\mathrm{Ge}_{1} \mathrm{Sb}_{4} \mathrm{Te}_{7}$ sample.

Information on the structural properties of the deposited samples was obtained by Raman spectroscopy and X-ray diffraction. The XRD patterns of the $\mathrm{GeSb}_{4} \mathrm{Te}_{7}, \mathrm{GeSb}_{2} \mathrm{Te}_{4}$, and $\mathrm{Ge}_{2} \mathrm{Sb}_{2} \mathrm{Te}_{5}$ thin films indicated the formation of a face-centered cubic (fcc) crystalline structure (Figure 2). The peaks found at approximately $29^{\circ}$ and $42^{\circ} 2 \theta$ angles were correlated to the (200) and (220) diffraction lines of the cubic phase. The GeTe and $\mathrm{Sb}_{2} \mathrm{Te}_{3}$ samples presented a different behavior. While the XRD measurements for the GeTe film suggested an amorphous deposition, the ones for $\mathrm{Sb}_{2} \mathrm{Te}_{3}$ sample presented peaks that can be associated with two types of structures: one characterized by wider peaks (thus, smaller crystallite dimensions) and another one represented by the narrower diffraction line at the same $2 \theta$ angle as the fcc structure of the GST based samples. The first mentioned phase can be due to the excess of $\mathrm{Sb}$ in the $\mathrm{Sb}_{2} \mathrm{Te}_{3}$ sample. The larger diffraction lines from our XRD pattern were found at the same $2 \theta$ angles as the ones observed by Prokhorov et al. [34] when analyzing thin films of Sb-Te with a higher $\mathrm{Sb}$ atomic content.

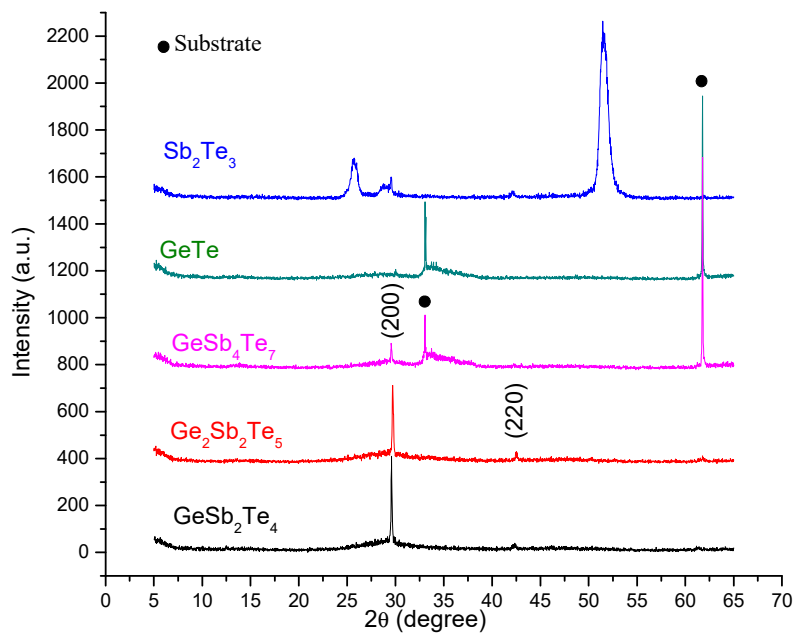

Figure 2. The XRD patterns of the chalcogenide thin films deposited using the 266-nm harmonic of the Nd-YAG laser. 
The Raman spectra of the five thin films mentioned before (Table 1) are presented in Figure 3. The reported studies on Raman spectroscopy of GeTe materials revealed that the amorphous GeTe (a-GeTe) presents four peaks at 83,125,162, and $218 \mathrm{~cm}^{-1}$, and the crystalline GeTe (c-GeTe) shows dominant vibrational modes at about 80 and $120 \mathrm{~cm}^{-1}$. Moreover, Andrikopoulos et al. [35] observed several similarities between the peaks of the a- and c-GeTe samples. These were related to the much wider peak of the crystalline phase and to the narrower peak of the amorphous sample compared to the Raman response of other materials. These Raman features indicated that GeTe chalcogenide crystals present a distorted rock salt structure, while the a-GeTe seems more ordered than other glasses. In our study, the wide band in the $110-200 \mathrm{~cm}^{-1}$ region observed for the GeTe thin film is probably due to a combination between a crystalline structure and an amorphous phase.

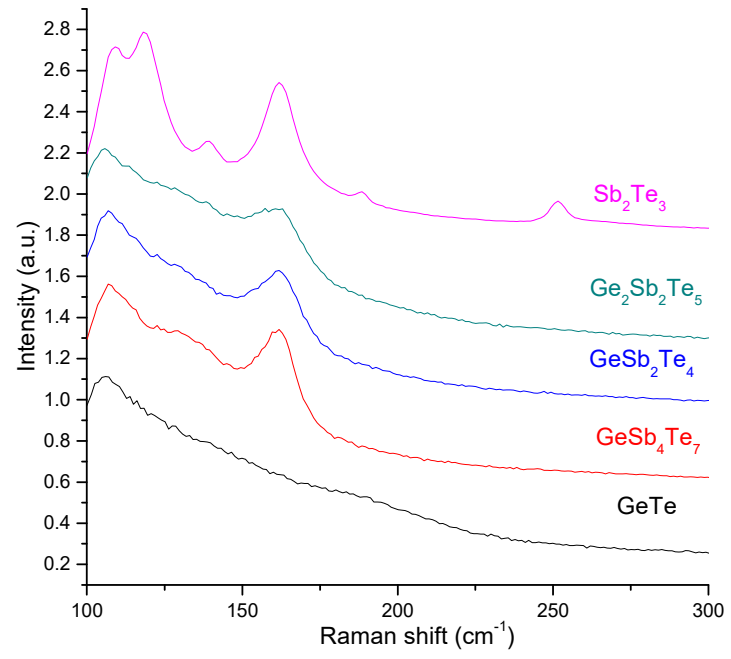

Figure 3. The Raman spectra of the five thin films deposited by ns-PLD at $266 \mathrm{~nm}$ (see Table 1 for deposition conditions).

$\mathrm{Sb}_{2} \mathrm{Te}_{3}$ has a rhombohedral ( $D_{3 d}^{5}$ symmetry) structure, with the following centre of the Brillouin zone representation:

$$
\Gamma=2\left(A_{1 g}+E_{g}\right)+3\left(E_{u}+A_{2 u}\right)
$$

where the ungerade( $\mathrm{u})$-modes are Raman active and gerade $(\mathrm{g})$-modes are IR active. Using density the functional perturbation theory, Sosso et al. [36] represented the IR and Raman spectra of crystalline $\mathrm{Sb}_{2} \mathrm{Te}_{3}$. The good agreement of their observations to the experimental vibrational spectra allowed them to assign each peak to specific phonons: $E_{g}$ at 46 and $113 \mathrm{~cm}^{-1}$ and $A_{1 g}$ at 62 and $166 \mathrm{~cm}^{-1}$. A sketch of the displacement patterns of phonons is also presented in Reference [37]. Two peaks at 110 and $165 \mathrm{~cm}^{-1}$ were also observed by Nemec et al. [6] in the Raman spectroscopy study on $\mathrm{Sb}_{2} \mathrm{Te}_{3}$ bulk materials used as targets in the deposition process. In our case, the spectra recorded for this type of material are described by two peaks: 110 and $163 \mathrm{~cm}^{-1}$. In accordance with the data published in References [6,36,37], the first peak was attributed to the active Raman $E_{g}$ mode, while the second one to the $\mathrm{A}_{1 \mathrm{~g}}$ vibrational mode. However, for the $\mathrm{Sb}_{2} \mathrm{Te}_{3}$ film deposited using the $266 \mathrm{~nm}$ radiation of the Nd-YAG laser, additional vibrational modes were detected which were associated with the antimony-rich phase observed through XRD measurements.

The Raman spectra of the Ge-Sb-Te based compounds indicated the formation of a crystalline structure, presenting two peaks at 110 and $160 \mathrm{~cm}^{-1}$. The same Raman response was obtained by Nemec et al. [6] when analyzing Ge-Sb-Te bulk materials. Based on the interpretation of the Raman spectra of GeTe and $\mathrm{Sb}_{2} \mathrm{Te}_{3}$ crystals, the bands of GST materials found at approximately $115-110 \mathrm{~cm}^{-1}$ and $165 \mathrm{~cm}^{-1}$ were assigned to the $\Gamma_{1}\left(\mathrm{~A}_{1}\right), \mathrm{E}_{\mathrm{g}}(2)$, and $\mathrm{A}_{1 \mathrm{~g}}(2)$ modes, respectively [6]. However, since the two peaks do not present a narrow width, we should consider the presence of an amorphous phase in the deposited samples, an observation that is sustained by the ellipsometry measurements as well. 
The presence of an amorphous phase can also be deduced from the XRD measurements where only the most intense peak of the fcc crystalline structure is observed.

\subsubsection{Femtosecond and Picosecond Laser Ablation}

Several thin films of Ge-Sb-Te based materials were also deposited by fs- and ps-PLD using a Ti-Sa laser with a wavelength of $800 \mathrm{~nm}, 1.6 \mathrm{~mJ}$ laser energy, and $1 \mathrm{kHz}$ repetition rate. Other experimental parameters were the deposition time (5 to $30 \mathrm{~min}$ ), target-substrate distance $(1.5$ to $6 \mathrm{~cm}$ ), and laser fluence $\left(0.1\right.$ to $\left.0.5 \mathrm{~J} / \mathrm{cm}^{2}\right)$. In the case of fs-PLD, the fluence used results in irradiance values in the approximate range of $1-4 \mathrm{TW} / \mathrm{cm}^{2}$. Although these values might seem quite high, comparable irradiances have been already used in other fs-PLD studies $[29,38,39]$, leading to good quality thin films. The electron density was not measured in the current work; we note, however, that laser ablation of solid targets in similar pulse duration and irradiance conditions led to values well below the critical density (which is in the range of $10^{21} \mathrm{~cm}^{-3}$ ). For instance, Anoop et al. [40], using $40 \mathrm{fs}$ pulses and fluences in the range $0.45-77 \mathrm{~J} / \mathrm{cm}^{2}$, measured an electron density of the order of $10^{17} \mathrm{~cm}^{-3}$ close to the target. When the electron density was measured farther from the target (which can present more practical interest for PLD experiments), values in the range $10^{10}-10^{13} \mathrm{~cm}^{-3}$ were observed [41-43].

Compared to the thin films deposited by ns-PLD, the optical microscopy and stylus profilometry measurements revealed that these samples present more uniform surface, without large droplets (see Figure 4). In most cases, the thickness variation with the modified experimental parameters is evident. For example, a decrease of the GeTe sample thickness from $900 \mathrm{~nm}$ to $140 \mathrm{~nm}$ was observed when the laser fluence was decreased from $0.3 \mathrm{~J} / \mathrm{cm}^{2}$ to $0.1 \mathrm{~J} / \mathrm{cm}^{2}$. Also, a twofold (from $1400 \mathrm{~nm}$ to $700 \mathrm{~nm}$ ) thinner GeTe film was obtained when the target-substrate distance was increased from 4 to $6 \mathrm{~cm}$.

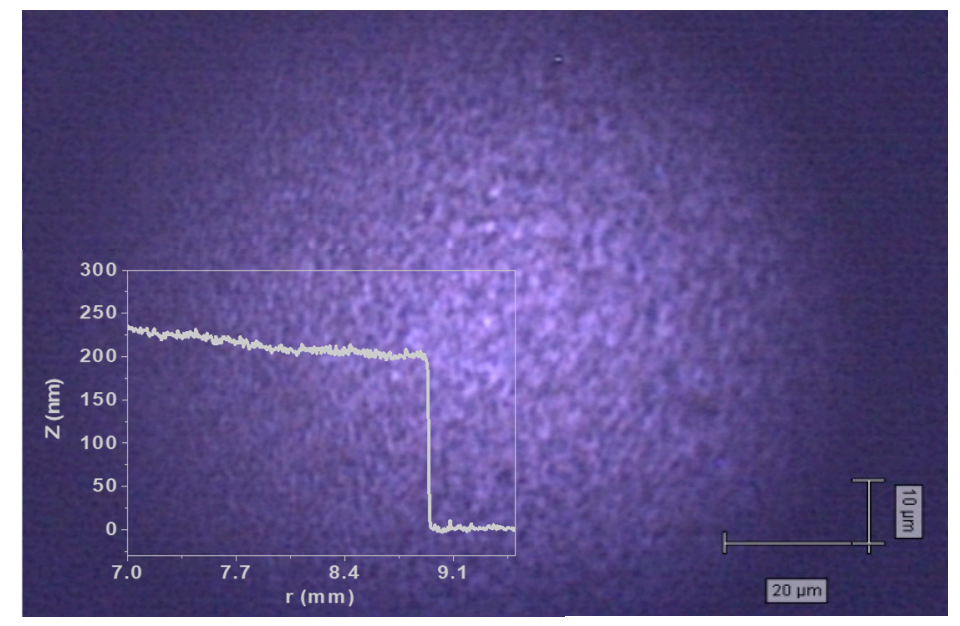

Figure 4. An optical microscopy image and surface topography of a $\mathrm{Ge}_{2} \mathrm{Sb}_{2} \mathrm{Te}_{5}$ thin film deposited by fs-PLD.

Beside a more uniform surface, the Ge-Sb-Te based thin films presented also an improved chemical composition. Table 2 summarizes the representative $\mathrm{Ge}, \mathrm{Sb}$, and Te concentrations of three $\mathrm{Ge}_{2} \mathrm{Sb}_{2} \mathrm{Te}_{5}$ thin films deposited using lasers with different pulse duration. Deviations from the nominal (stoichiometric) concentrations were also recorded for the films deposited by fs- and ps-PLD; however, they were smaller (usually below 4 at $\%$ ) than the ones observed for the ns-deposited thin films. 
Table 2. Representative concentrations for $\mathrm{Ge}, \mathrm{Sb}$, and $\mathrm{Te}$ of three $\mathrm{Ge}_{2} \mathrm{Sb}_{2} \mathrm{Te}_{5}$ thin films deposited in different temporal regimes.

\begin{tabular}{|c|c|c|c|c|}
\hline \multirow{4}{*}{$\begin{array}{l}\text { Pulse } \\
\text { Duration }\end{array}$} & \multirow{4}{*}{ Deposition Conditions } & \multicolumn{3}{|c|}{ Nominal Composition } \\
\hline & & \multicolumn{3}{|c|}{ Atomic \% } \\
\hline & & $\mathrm{Ge}$ & $\mathrm{Sb}$ & Te \\
\hline & & 22.22 & 22.22 & 55.55 \\
\hline Nanosecond & $\begin{array}{c}\text { Nd-YAG laser }(266 \mathrm{~nm}) ; \text { Target-to-substrate } \\
\text { distance }=3 \mathrm{~cm} ; \text { Fluence }=3.8 \mathrm{~J} / \mathrm{cm}^{2} \text { Deposition } \\
\text { time }=30 \mathrm{~min}\end{array}$ & 25.23 & 26.81 & 47.97 \\
\hline Picosecond & $\begin{array}{l}\text { Ti-Sa laser; Target-to-substrate distance }=4 \mathrm{~cm} ; \\
\text { Fluence }=0.3 \mathrm{~J} / \mathrm{cm}^{2} ; \text { Deposition time }=60 \mathrm{~min}\end{array}$ & 23.45 & 21.69 & 54.86 \\
\hline Femtosecond & $\begin{array}{l}\text { Ti-Sa laser; Target-to-substrate distance }=4 \mathrm{~cm} \\
\text { Fluence }=0.3 \mathrm{~J} / \mathrm{cm}^{2} ; \text { Deposition time }=30 \mathrm{~min}\end{array}$ & 22.58 & 22.28 & 55.13 \\
\hline
\end{tabular}

The elemental composition of the deposited samples was also probed by ToF-SIMS depth profiling. An example is given in Figure 5 for the $\mathrm{Ge}_{2} \mathrm{Sb}_{2} \mathrm{Te}_{5}$ thin film deposited by ps-PLD. As observed for the ns-PLD samples, a uniform distribution was recorded for the three elements.

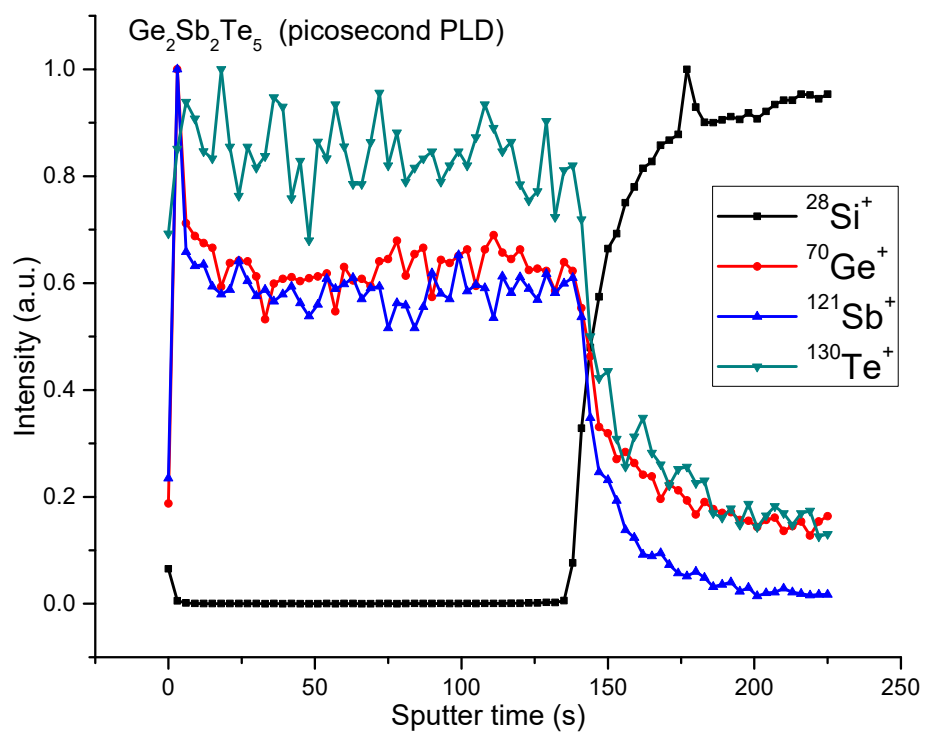

Figure 5. The ToF-SIMS depth profiles for the $\mathrm{Ge}_{2} \mathrm{Sb}_{2} \mathrm{Te}_{5}$ thin film deposited by ps-PLD (target-to-substrate distance $=3 \mathrm{~cm}$, fluence $=0.3 \mathrm{~J} / \mathrm{cm}^{2}$, deposition time $=60 \mathrm{~min}$ ).

The structural properties of the samples deposited using the Ti-Sa laser were analyzed using the same two methods mentioned in the previous section. The XRD patterns revealed an amorphous phase deposition for the $\mathrm{Sb}_{2} \mathrm{Te}_{3}$ and $\mathrm{Ge}_{2} \mathrm{Sb}_{2} \mathrm{Te}_{5}$ samples. Figure 6a presents the Raman spectra of two GeTe thin films deposited using different fluences of $0.1 \mathrm{~J} / \mathrm{cm}^{2}$ and $0.5 \mathrm{~J} / \mathrm{cm}^{2}$ (the target-substrate distance $(6 \mathrm{~cm})$, deposition time (30 $\mathrm{min})$, and pressure ( $\left.10^{-5} \mathrm{Torr}\right)$ were kept constant). While the first film present two narrow peaks centered at 120 and $140 \mathrm{~cm}^{-1}$, the sample deposited using a higher fluence (thus, an increased thickness) showed a wider band with the maximum value positioned at $120 \mathrm{~cm}^{-1}$ which can be associated with the amorphous structure of the GeTe material [6]. For a clear assignment of the peaks found for the film deposited at $0.1 \mathrm{~J} / \mathrm{cm}^{2}$, we took into consideration the Raman response of the Te phase. The bulk Te Raman spectra presents two peaks: one at $121 \mathrm{~cm}^{-1}$ which represents the $A_{1}$ mode and a second one at $140.8 \mathrm{~cm}^{-1}$ which represent $\mathrm{E}_{\mathrm{TO}}$ modes in crystalline Te-Te chain [44]. Considering that Te crystallizes at room temperature [45], a more adequate assignment of the two Raman peaks observed in our study would be based on Te segregation, which could be related as often reported to the photosensitivity of the GeTe film under laser irradiation of the Raman 
spectrometer when the film thickness is thinner rather than GeTe crystallization. We note, however, that parallel measurements using $785 \mathrm{~nm}$ excitation showed no difference in the resulting Raman spectra. Moreover, the main Raman feature of Ge is a vibrational mode at $300 \mathrm{~cm}^{-1}$. However, the peak from our study found at the same wavenumber is due to the contribution of the silicon substrate and not to Ge segregation, considering its high crystallization temperature $\left(250{ }^{\circ} \mathrm{C}\right)$ [46].

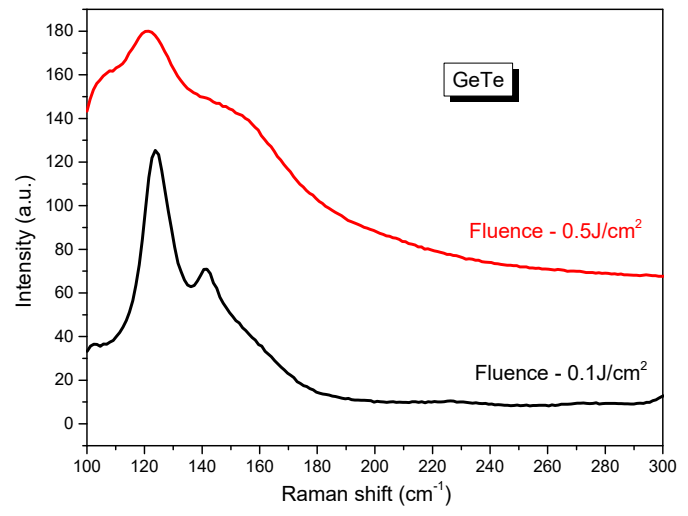

(a)

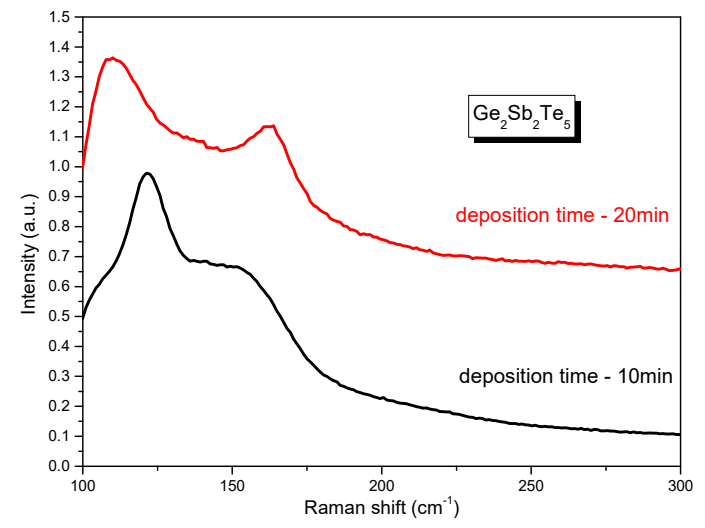

(b)

Figure 6. Raman spectra of the (a) GeTe and (b) $\mathrm{Ge}_{2} \mathrm{Sb}_{2} \mathrm{Te}_{5}$ thin films deposited in different conditions by fs-PLD.

Figure $6 \mathrm{~b}$ shows the Raman spectroscopy results of two $\mathrm{Ge}_{2} \mathrm{Sb}_{2} \mathrm{Te}_{5}$ thin films deposited in 10 and 20 min respectively (the target-substrate distance $(6 \mathrm{~cm})$, fluence $\left(0.2 \mathrm{~J} / \mathrm{cm}^{2}\right)$ and pressure $\left(10^{-5}\right.$ Torr $)$ were kept constant). Again, a different Raman response was observed for the two samples with different thicknesses. While the first $(10 \mathrm{~min})$ film is characterized by an amorphous phase, the second one presents two peaks around $110 \mathrm{~cm}^{-1}$ and $160 \mathrm{~cm}^{-1}$ which could be associated with $\mathrm{E}_{\mathrm{g}}$ and $\mathrm{A}_{1 \mathrm{~g}}$ vibrational modes, respectively [6].

\subsection{Optical Properties}

Due to possible applications in phase-change optical storage and optical waveguides [47], an important parameter to be considered for this chalcogenide thin films is their reflectivity, which can be derived from $[47,48]$ :

$$
R(E)=\frac{(n(E)-1)^{2}+k^{2}(E)}{(n(E)+1)^{2}+k^{2}(E)}
$$

where $E, n$, and $k$ are the photon energy, refractive index, and extinction coefficient, respectively (we recall that the refractive index is related to the complex dielectric constant for which the imaginary part can be measured experimentally and the real part can be evaluated using the Kramers-Krönig transformation). The optical properties (refractive indices and extinction coefficients) of several samples were investigated using variable angle spectroscopic ellipsometry (VASE, J.A. Woollam) with an automated rotating analyzer.

When analyzing the $\mathrm{Ge}_{2} \mathrm{Sb}_{2} \mathrm{Te}_{5}$ series of thin films, we observed that the optical properties were not significantly influenced by the varied experimental parameters; thus, we continued by focusing on the $\mathrm{Ge}-\mathrm{Sb}-\mathrm{Te}$ thin films deposited in the same conditions. Figure 7a-c presents the spectral dependence of the refractive index, the extinction coefficient, and the reflectivity for the samples deposited by ns laser ablation. The optical band gap values were derived from the Tauc plots $(\alpha E)^{1 / 2}=f(E)$ (see Figure 7d). The absorption coefficient $(\alpha)$ was calculated using the well-known relationship with the imaginary part of the refraction index [49]:

$$
\alpha=\frac{4 \pi k}{\lambda}
$$


The obtained optical band gap values are presented in the inset of Figure $7 \mathrm{~d}$.
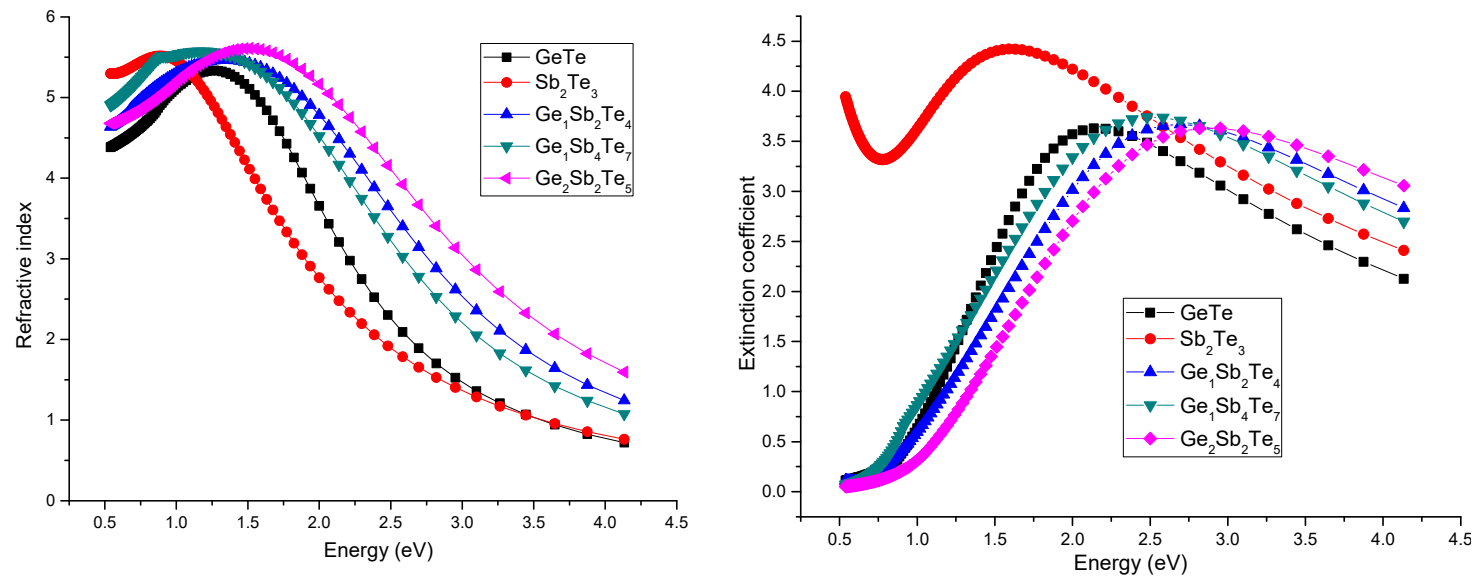

(a)

(b)


(c)

(d)

Figure 7. The ellipsometry results: the energy dependence of refractive index (a), extinction coefficient (b), reflectivity (c), and $(\alpha \mathrm{E})^{1 / 2}$ (d) for the Ge-Sb-Te based thin films deposited using the $266 \mathrm{~nm}$ radiation of the Nd-YAG laser.

Comparing these results with the ones reported by Nemec et al. [31,50], some similarities were observed: The refractive index presented an increase up to $1.2 \mathrm{eV}$ and then a decrease for higher energies. The same type of dependence was observed for the extinction coefficient which reached its maximum value around $2.5 \mathrm{eV}$. However, the optical response of our samples presented features between those found for the amorphous and crystalline samples reported in Reference [31]. Comparing the plots of the refractive indexes, we observed higher maximum values than the amorphous chalcogenide thin films deposited by Nemec et al. [31] (and in the same time lower than the crystallized samples), but a more rapid decrease at large energy values was recorded, comparable with the optical features of the crystalline thin films. These results indicate a partial crystallization of our deposited samples. Moreover, we did not observe a clear dependence of the maximum values of the refractive index or extinction coefficient with the $\mathrm{Sb}_{2} \mathrm{Te}_{3}$ content. This can be explained by the different structural characteristics mentioned in the previous sections. Regarding the bandgap energies, our calculations (see inset Figure 7d) showed values comparable with the ones reported in Reference [31]. However, the poor microstructural quality of the deposited films led, in some cases, to slightly increased error values. Lee et al. [51] found that the optical bandgaps of their $\mathrm{Ge}_{2} \mathrm{Sb}_{2} \mathrm{Te}_{5}$ samples (deposited by RF magnetron) with amorphous, fcc, and hexagonal structures were $0.7,0.5$, and $0.5 \mathrm{eV}$, respectively, our data being closer to the values observed for the crystalline phase. An unusual value of the optical 
band gap was observed for the $\mathrm{Sb}_{2} \mathrm{Te}_{3}$ sample. However, the XRD results of this thin film revealed the presence of two phases, one of them induced by the increased Sb content. Preliminary ellipsometry measurements were also performed on fs and ps deposited samples, but due to the lower thickness of these samples, only the transparent region (up to $1 \mathrm{eV}$ ) could be investigated for the moment. These measurements will be extended in the near future using thicker fs and ps samples. Due to the narrow range in which we obtained a signal, no calculations of the $\mathrm{E}_{\mathrm{g}}{ }^{\mathrm{opt}}$ were allowed.

\section{Conclusions}

Ge-Sb-Te thin films were deposited using various experimental conditions and lasers with ns, ps, and fs pulse duration. Analyzing the thin films deposited by nanosecond laser ablation, we observed that the sample thickness was influenced by the laser wavelength, fluence, target-to-substrate distance, and deposition time. Most of the deposited samples in this temporal regime presented droplets on the surface which decreased as the laser fluence was diminished. The EDS results revealed Te atomic percentages lower than the nominal value for all five compositions considered, which was explained by its lower vaporization heat. An over-stoichiometric Sb concentration was observed for the Ge-Sb-Te-based samples. The ToF-SIMS images and depth profiles revealed a uniform distribution of the main elements and of their combinations on the surface and in the volume of the films. The Raman spectroscopy and XRD analysis confirmed the formation of an fcc structure together with an amorphous growth for the Ge-Sb-Te based samples. While the XRD pattern of the GeTe thin film revealed an amorphous deposition, the $\mathrm{Sb}_{2} \mathrm{Te}_{3}$ thin film presented additional diffraction lines indicating multiphase formation. Ellipsometric measurements done on the Ge-Sb-Te thin films revealed $n$ and $k$ values between the ones of amorphous and crystalline samples reported in Reference [31], confirming the structural analysis results. The thin films deposited with femtosecond- and picosecond-pulsed lasers presented an improved morphology with no large droplets on the surface. Also, in their case, the thickness was found to be influenced by the deposition time, laser fluence, and target-substrate distance. The Ge, $\mathrm{Sb}$, and Te concentrations obtained by EDS were much closer to the nominal values than the ones of the ns-PLD, their variations being smaller than the measurement error bar. The structural analysis results revealed an amorphous deposition for the Ge-Sb-Te-based fs-PLD films. The lower fluence used in fs-PLD determined the ejection of particles with lower kinetic energies than the ones generated by nanosecond ablation. This can influence the energetic transfer at substrate surface and thus the crystallization process. Moreover, on a fundamental background, the different ejection mechanisms involved for the various laser pulse durations (see above) favor a droplet formation in the case of ns-pulses vs a nanoparticle formation for ultrashort pulses. Overall, our results confirm that (high-repetition-rate) femtosecond PLD is a useful technique to obtain uniform, amorphous, and stoichiometric thin films in a short deposition time.

Author Contributions: Conceptualization, C.F. and O.P.; investigation, C.F., S.G., O.P., P.N., V.N., N.C. and B.C.; writing-original draft preparation, O.P. and G.B.; writing—review and editing, G.B. and C.F.

Funding: This research was supported by the PHC projects Brancusi $n^{\circ} 29551 \mathrm{XB}$ and Barrande $n^{\circ} 28449 \mathrm{NK}$; the Romanian Space Agency (ROSA) within the Space Technology and Advanced Research (STAR) Program, grant number 169/20.07.2017; the Czech Science Foundation (Project No. 18-03823S); and the Ministry of Education, Youth, and Sports of the Czech Republic (ProjectLM2015082).

Conflicts of Interest: The authors declare no conflict of interest.

\section{References}

1. Yamada, N.; Ohno, E.; Akahira, N.; Nishiuchi, K.; Nagata, K.; Takao, M. High Speed Overwritable Phase Change Optical Disk Material. Jpn. J. Appl. Phys. 1987, 26, 61-66. [CrossRef]

2. Wang, L.; Yang, C.; Wen, J.; Xiong, B. Amorphization Optimization of $\mathrm{Ge}_{2} \mathrm{Sb}_{2} \mathrm{Te}_{5}$ Media for Electrical Probe Memory Applications. Nanometer 2018, 8, 368. [CrossRef] [PubMed] 
3. Kolobov, A.V.; Fons, P.; Tominaga, J.; Frenkel, A.I.; Ankudinov, A.L.; Yannopoulos, S.N.; Andrikopoulos, K.S.; Uruga, T. Why Phase-Change Media Are Fast and Stable: A New Approach to an Old Problem. Jpn. J. Appl. Phys. 2005, 44, 3345-3349. [CrossRef]

4. Kolobov, A.V.; Fons, P.; Tominaga, J.; Uruga, T. Why DVDs work the way they do: The nanometer-scale mechanism of phase change in Ge-Sb-Te alloys. J. Non-Cryst. Solids 2006, 352, 1612-1615. [CrossRef]

5. Kolobov, A.V.; Tominaga, J. Metastability and Phase Change Phenomena. In Chalcogenides; Springer: Berlin/Heidelberg, Germany, 2012.

6. Nemec, P.; Nazabal, V.; Moreac, A.; Gutwirth, J.; Beneš, L.; Frumar, M. Amorphous and crystallized Ge-Sb-Te thin films deposited by pulsed laser: Local structure using Raman scattering spectroscopy. Mater. Chem. Phys. 2012, 136, 935-941. [CrossRef]

7. Raoux, S.; Ielmini, D.; Wuttig, M.; Karpov, I. Phase Change Materials. MRS Bull. 2012, 37, 118-123. [CrossRef]

8. Zhang, W.; Mazzarello, R.; Wuttig, M.; Ma, E. Designing crystallization in phase-change materials for universal memory and neuro-inspired computing. Nat. Rev. Mater. 2019, 4, 150-168. [CrossRef]

9. Olivier, M.; Němec, P.; Boudebs, G.; Boidin, R.; Focsa, C.; Nazabal, V. Photosensitivity of pulsed laser deposited Ge-Sb-Se thin films. Opt. Mater. Express 2015, 5, 781. [CrossRef]

10. Yamada, N. Origin, secret, and application of the ideal phase-change material GeSbTe. Phys. Status Solidi 2012, 249, 1837-1842. [CrossRef]

11. Wang, J.J.; Xu, Y.Z.; Mazzarello, R.; Wuttig, M.; Zhang, W. A review on disorder-driven metal-insulator transition in crystalline vacancy-rich GeSbTe phase-change materials. Materials 2017, 10, 862. [CrossRef]

12. Vlček, M.; Schroeter, S.; Čech, J.; Wágner, T.; Glaser, T. Selective etching of chalcogenides and its application for fabrication of diffractive optical elements. J. Non-Cryst. Solids 2003, 326-327, 515-518. [CrossRef]

13. Gutwirth, J.; Wagner, T.; Bezdicka, P.; Hrdlicka, M.; Vlcek, M.; Frumar, M. On angle resolved RF magnetron sputtering of GeSbTe thin films. J. Non-Cryst. Solids 2009, 355, 1935-1938. [CrossRef]

14. Nazabal, V.; Charpentier, F.; Adam, J.L.; Nemec, P.; Lhermite, H.; Brandily-Anne, M.L.; Charrier, J.; Guin, J.P.; Moréac, A. Sputtering and pulsed laser deposition for near- and mid-infrared applications: A comparative study of $\mathrm{Ge}_{25} \mathrm{Sb}_{10} \mathrm{~S}_{65}$ and $\mathrm{Ge}_{25} \mathrm{Sb}_{10} \mathrm{Se}_{65}$ amorphous thin films. Int. J. Appl. Ceram. Technol. 2011, 8, 990-1000. [CrossRef]

15. Musgraves, J.D.; Carlie, N.; Hu, J.; Petit, L.; Agarwal, A.; Kimerling, L.C.; Richardson, K.A. Comparison of the optical, thermal and structural properties of $\mathrm{Ge}-\mathrm{Sb}-\mathrm{S}$ thin films deposited using thermal evaporation and pulsed laser deposition techniques. Acta Mater. 2011, 59, 5032-5039. [CrossRef]

16. Lee, J.; Choi, S.; Lee, C.; Kang, Y.; Kim, D. GeSbTe deposition for the PRAM application. Appl. Surf. Sci. 2007, 253, 3969-3976. [CrossRef]

17. Mussler, G.; Ratajczak, A.; von der Ahe, M.; Du, H.; Grützmacher, D. Metal organic vapor phase epitaxy of $\mathrm{Ge}_{1} \mathrm{Sb}_{2} \mathrm{Te}_{4}$ thin films on Si(111) substrate. Appl. Phys. A 2019, 125, 1-7. [CrossRef]

18. Hilmi, I.; Rauschenbach, B.; Gerlach, J.W.; Thelander, E.; Schumacher, P.; Gerlach, J.W.; Rauschenbach, B. Epitaxial $\mathrm{Ge}_{2} \mathrm{Sb}_{2} \mathrm{Te}_{5}$ films on $\mathrm{Si}(111)$ prepared by pulsed laser deposition. Thin Solid Films 2016, 619, 81-85. [CrossRef]

19. Thelander, E.; Gerlach, J.W.; Ross, U.; Lotnyk, A.; Rauschenbach, B. Low temperature epitaxy of Ge-Sb-Te films on $\mathrm{BaF}_{2}$ (111) by pulsed laser deposition. Appl. Phys. Lett. 2014, 105, 1-6. [CrossRef]

20. Song, J.H.; Susaki, T.; Hwang, H.Y. Enhanced Thermodynamic Stability of Epitaxial Oxide Thin Films. Adv. Mater. 2008, 20, 2528-2532. [CrossRef]

21. Boschker, J.E.; Folven, E.; Monsen, A.F.; Wahlström, E.; Grepstad, J.K.; Tybell, T. Consequences of high adatom energy during pulsed laser deposition of $\mathrm{La}_{0.7} \mathrm{Sr}_{0.3} \mathrm{MnO}_{3}$. Cryst. Growth Des. 2012, 12, 562-566. [CrossRef]

22. Mihesan, C.; Gurlui, S.; Ziskind, M.; Chazallon, B.; Martinelli, G.; Zeghlache, H.; Guignard, M.; Nazabal, V.; Smektala, F.; Focsa, C. Photo-excited desorption of multi-component systems: Application to chalcogenide glasses. Appl. Surf. Sci. 2005, 248, 224-230. [CrossRef]

23. Irimiciuc, S.; Boidin, R.; Bulai, G.; Gurlui, S.; Nemec, P.; Nazabal, V.; Focsa, C. Laser ablation of $\left(\mathrm{GeSe}_{2}\right)_{100-x}\left(\mathrm{Sb}_{2} \mathrm{Se}_{3}\right)_{x}$ chalcogenide glasses: Influence of the target composition on the plasma plume dynamics. Appl. Surf. Sci. 2016, 418, 594-600. [CrossRef]

24. Pompilian, O.G.; Gurlui, S.; Nemec, P.; Nazabal, V.; Ziskind, M.; Focsa, C. Plasma diagnostics in pulsed laser deposition of GaLaS chalcogenides. Appl. Surf. Sci. 2013, 278, 352-356. [CrossRef] 
25. Ursu, C.; Pompilian, O.G.; Gurlui, S.; Nica, P.; Agop, M.; Dudeck, M.; Focsa, C. $\mathrm{Al}_{2} \mathrm{O}_{3}$ ceramics under high-fluence irradiation: plasma plume dynamics through space- and time-resolved optical emission spectroscopy. Appl. Phys. A 2010, 101, 153-159. [CrossRef]

26. Pompilian, O.G.; Dascalu, G.; Mihaila, I.; Gurlui, S.; Olivier, M.; Nemec, P.; Nazabal, V.; Cimpoesu, N.; Focsa, C. Pulsed laser deposition of rare-earth-doped gallium lanthanum sulphide chalcogenide glass thin films. Appl. Phys. A 2014, 117, 197-205. [CrossRef]

27. Dascalu, G.; Pompilian, G.; Chazallon, B.; Caltun, O.F.; Gurlui, S.; Focsa, C. Femtosecond pulsed laser deposition of cobalt ferrite thin films. Appl. Surf. Sci. 2013, 278, 38-42. [CrossRef]

28. Focsa, C.; Nemec, P.; Ziskind, M.; Ursu, C.; Gurlui, S.; Nazabal, V. Laser ablation of AsxSe100-x chalcogenide glasses: Plume investigations. Appl. Surf. Sci. 2009, 255, 5307-5311. [CrossRef]

29. Dascalu, G.; Pompilian, G.; Chazallon, B.; Nica, V.; Caltun, O.F.; Gurlui, S.; Focsa, C. Rare earth doped cobalt ferrite thin films deposited by PLD. Appl. Phys. A 2012, 110, 915-922. [CrossRef]

30. Chrisey, D.B.; Hubler, G.K. Pulsed Laser Deposition of Thin Films; John Wiley \& Sons, Inc.: New York, NY, USA, 1994.

31. Nemec, P.; Přikryl, J.; Nazabal, V.; Frumar, M. Optical characteristics of pulsed laser deposited Ge-Sb-Te thin films studied by spectroscopic ellipsometry. J. Appl. Phys. 2011, 109, 073520. [CrossRef]

32. Bouška, M.; Pechev, S.; Simon, Q.; Boidin, R.; Nazabal, V.; Gutwirth, J.; Baudet, E.; Němec, P. Pulsed laser deposited GeTe-rich GeTe-Sb ${ }_{2} \mathrm{Te}_{3}$ thin films. Sci. Rep. 2016, 6, 26552. [CrossRef]

33. Krusin-Elbaum, L.; Cabral, C.; Chen, K.N.; Copel, M.; Abraham, D.W.; Reuter, K.B.; Rossnagel, S.M.; Bruley, J.; Deline, V.R. Evidence for segregation of $\mathrm{Te}_{\mathrm{in}} \mathrm{Ge}_{2} \mathrm{Sb}_{2} \mathrm{Te}_{5}$ films: Effect on the "phase-change" stress. Appl. Phys. Lett. 2007, 90, 141902. [CrossRef]

34. Prokhorov, E.; Gonzalez-Hernandez, J.; Hernandez-Landaverde, M.A.; Chao, B.; Morales-Sanchez, E. Crystallization mechanism in Sb:Te thin film.pdf. J. Phys. Chem. Solids 2007, 68, 883-886. [CrossRef]

35. Andrikopoulos, K.S.; Yannopoulos, S.N.; Voyiatzis, G.A.; Kolobov, A.V.; Ribes, M.; Tominaga, J. Raman scattering study of the a-GeTe structure and possible mechanism for the amorphous to crystal transition. J. Phys. Condens. Matter 2006, 18, 965-979. [CrossRef]

36. Sosso, G.C.; Caravati, S.; Bernasconi, M. Vibrational properties of crystalline $\mathrm{Sb}_{2} \mathrm{Te}_{3}$ from first principles. J. Phys. Condens. Matter 2009, 21, 095410. [CrossRef] [PubMed]

37. Xu, Z.; Chen, C.; Wang, Z.; Wu, K.; Chong, H.; Ye, H. Optical constants acquisition and phase change properties of $\mathrm{Ge}_{2} \mathrm{Sb}_{2} \mathrm{Te}_{5}$ thin films based on spectroscopy. RSC Adv. 2018, 8, 21040-21046. [CrossRef]

38. Murray, M.; Jose, G.; Richards, B.; Jha, A. Femtosecond pulsed laser deposition of silicon thin films. Nanoscale Res. Lett. 2013, 8, 1-6. [CrossRef]

39. Katsuno, T.; Godet, C.; Orlianges, J.C.; Loir, A.S.; Garrelie, F.; Catherinot, A. Optical properties of high-density amorphous carbon films grown by nanosecond and femtosecond pulsed laser ablation. Appl. Phys. A 2005, 81, 471-476. [CrossRef]

40. Anoop, K.K.; Harilal, S.S.; Philip, R.; Bruzzese, R.; Amoruso, S. Laser fluence dependence on emission dynamics of ultrafast laser induced copper plasma. J. Appl. Phys. 2016, 120, 185901. [CrossRef]

41. Anoop, K.K.; Ni, X.; Wang, X.; Amoruso, S.; Bruzzese, R. Fast ion generation in femtosecond laser ablation of a metallic target at moderate laser intensity. Laser Phys. 2014, 24, 105902. [CrossRef]

42. Irimiciuc, S.A.; Gurlui, S.; Bulai, G.; Nica, P.; Agop, M.; Focsa, C. Langmuir probe investigation of transient plasmas generated by femtosecond laser ablation of several metals: Influence of the target physical properties on the plume dynamics. Appl. Surf. Sci. 2017, 417, 108-118. [CrossRef]

43. Nica, P.; Gurlui, S.; Osiac, M.; Agop, M.; Ziskind, M.; Focsa, C. Investigation of femtosecond laser-produced plasma from various metallic targets using the Langmuir probe characteristic. Phys. Plasmas 2017, 24, 103119. [CrossRef]

44. Vinod, E.M.; Singh, A.K.; Ganesan, R.; Sangunni, K.S. Effect of selenium addition on the GeTe phase change memory alloys. J. Alloys Compd. 2012, 537, 127-132. [CrossRef]

45. Vinod, E.M.; Naik, R.; Ganesan, R.; Sangunni, K.S. Signatures of $\mathrm{Ge}_{2} \mathrm{Sb}_{2} \mathrm{Te}_{5}$ film at structural transitions. J. Non-Cryst. Solids 2012, 358, 2927-2930. [CrossRef]

46. Van Eijk, J.M. Structural Analysis of Phase-Change Materials Using X-ray Absorption Measurements. Ph.D. Thesis, RWTH Aachen University, Aachen, Germany, 17 December 2010.

47. Wei, S.; Wu, S.; Pei, F.; Li, J.; Wang, S.; Chen, L. Theoretical and Experimental Investigations of the Optical Properties of $\mathrm{Ge}_{2} \mathrm{Sb}_{2} \mathrm{Te}_{5}$ for Multi-State Optical Data Storage. J. Korean Phys. Soc. 2008, 53, 2265-2269. 
48. Hilton, A.R. Chalcogenide Glasses for Infrared. Optical Materials. Appl. Opt. 1966, 5, 1877-1882. [CrossRef] [PubMed]

49. Nechache, R.; Harnagea, C.; Li, S.; Cardenas, L.; Huang, W.; Chakrabartty, J.; Rosei, F. Bandgap tuning of multiferroic oxide solar cells. Nat. Photonics 2014, 61, 61-67. [CrossRef]

50. Nemec, P.; Moreac, A.; Nazabal, V.; Pavlišta, M.; Přikryl, J.; Frumar, M. Ge-Sb-Te thin films deposited by pulsed laser An ellipsometry and Raman scattering spectroscopy study. J. Appl. Phys. 2009, 106, 103509. [CrossRef]

51. Lee, B.-S.; Abelson, J.R.; Bishop, S.G.; Kang, D.-H.; Cheong, B.; Kim, K.-B. Investigation of the optical and electronic properties of $\mathrm{Ge}_{2} \mathrm{Sb}_{2} \mathrm{Te}_{5}$ phase change material in its amorphous, cubic, and hexagonal phases. J. Appl. Phys. 2005, 97, 093509. [CrossRef]

(C) 2019 by the authors. Licensee MDPI, Basel, Switzerland. This article is an open access article distributed under the terms and conditions of the Creative Commons Attribution (CC BY) license (http://creativecommons.org/licenses/by/4.0/). 